\title{
Describing Problems Experienced by Spanish Novice Physical Education Teachers
}

\author{
Pedro Sáenz-López ${ }^{1, *}$, Bartolomé J. Almagro ${ }^{1}$ and Sergio J. Ibáñez ${ }^{2}$ \\ ${ }^{1}$ Faculty of Education Sciences, University of Huelva, Spain \\ ${ }^{2}$ Faculty of Sports Sciences, University of Extremadura, Spain
}

\begin{abstract}
The aim of the present study was identify the most significant problems that Spanish novice physical education teachers encountered during their first teaching experiences. A mixed methodology (quantitative and qualitative) was utilized through questionnaires and interviews. The Inventory of Teaching Problems developed by Jordell (1985) was translated, revalidated to physical education and completed by 45 novice teachers. From the entire sample, 6 teachers we randomly selected to be interviewed by the main researcher. The results allowed identifying and emphasizing the following problems: organization and control of the class, the low social status of physical education, the scarcity of material resources and facilities, the relationships, the planning, and the teaching methodology. However, the gender effect was not statistically significant. The results allow suggesting that the establishment of specific, continuing educational programmes for novice teachers seems imperative.
\end{abstract}

Keywords: Teacher physical education, continuing education, specific didactics, novice teachers.

\section{INTRODUCTION}

The initial years of experience are crucial to novice teachers who must overcome numerous difficulties under unfavourable circumstances [1]. Currently, due to the changing conditions of society, to give a response to the new and complex situations that teachers encounter, it is necessary to think of teachers as "adaptive experts" [2], which is to say they are prepared for efficient learning throughout life.

In the Spanish context, teacher trainning in Physical Education is an issue on which many professionals and researchers are paying special attention [3, 4]. Moreover, within the last years, Physical Education has been experiencing a revaluation as a subject capable of stablishing a comprehensive education of the person through motor expressions, fostered by the important increase of professionals involved with this knowledge field. In order to put this study into context it is necessary to mention that this investigation was carried out with Primary School teachers (6 to 12 year-old students) and therefore they had a Teacher degree, specialist in Physical Education.

The study of the problems and concerns of novice teachers is an area within teacher education that requires special attention because the difficulties of the early experiences tend to be especially important $[5,6]$. For many novice teachers, the first year is difficult because the difference between the ideals they had during their education and what actually occurs in the schools is greater than they expected. Further, in many cases, novice teachers feel overwhelmed by the quantity and variety of tasks that they must perform at school [7].

*Address correspondence to this author at the Faculty of Education Sciences, University of Huelva, Avda. tres de marzo s/n, 21071 Huelva, Spain; Tel: (+34)959219266; Fax:(+34)959219265; E-mail: psaenz@uhu.es
The first years of experience of novice teachers are usually characterised by the quantity of intensive learning situations in unfamiliar contexts that provoke tension, insecurity, and lack of confidence. Some authors refer to this period as a "reality shock" $[5,8,9]$, because the majority of novice teachers experience their first few years of service as problematic and stressful.

A wide grouping of case studies describes the failure of teachers in their first year of teaching [8]. As Vonk [11] asserts, this situation worsens, because the beginning or novice teacher has exactly the same responsibilities as his or her colleagues who have many more years of experience, and the students, teachers, colleagues, and administrators often expect the beginning teacher to act as a complete professional. As such, it would be in the interest of the beginning teacher to have a tutor or mentor with whom to collaborate when confronting his or her initial teaching experiences, as researchers have found that tutored teaching experiences have a positive impact on the ability of beginning teachers to teach [12]. Then, socialization with other teachers was consider to influence beginning teachers in their way of executing their work [13-15], since learning from other teachers and cooperation amongst them is very beneficial for the education of the novice teacher [16].

Among teaching situations, discipline in the classroom is without a doubt one of the problems that most affect beginning teachers as well as one of the problems that is most often studied in research [17-19]. In fact, Veenman [5] compiled the primary problems of beginning teachers from different studies and concluded that the first and foremost is discipline. For Kohn [20], the ability to control the class is a prerequisite for being able to fulfil the proposed teaching objectives. Authors such as Geva-May and Dori [21] extend the problem of discipline to other difficulties in teachers' first few experiences such as managing and organizing the class. 
On the other hand, the failure of many educators centres on the fact that they do not motivate their students adequately. In the review by Veenman [5], this problem appears in second place. Along these lines, in a more recent review $[22,23]$, support that the problems found by Veenman are still current: how to manage the class, how to motivate the students, how to relate to the parents and colleagues, and in general, how to survive personally and professionally.

Long-term evaluation and planning are logical problems for the teacher in his or her first year of experience due to the fact that they have never faced a full school year [17, 23]. Various studies [24, 25] confirm that physical education teachers have doubts, deficiencies, and problems when it comes to planning.

In some cases, their experience as students at lower educational levels contributes to their shaping a belief system toward teaching that helps them to interpret their educational experiences. These beliefs are sometimes so established that their college education does not deeply change them whatsoever [26]. This important relationship between personal experience in school and its influence on physical education programmes was recently demonstrated by Morgan and Hansen [27]. These authors established the following predictors of quality in physical education programmes: personal experiences in primary school, quality of college education, and attitudes toward physical education teaching.

Novice physical education teachers tend to have these same problems, but they also have the added difficulty of teaching a class that has low status. Several studies [28-30] confirm the isolation of this class in schools, undervalued by students, colleagues, and administration.

Physical education has several distinct characteristics, beginning with the class' place, which is different from other classes, as it is done in a gymnasium or other athletic field instead of a classroom. These special conditions of physical education with regard to facilities and material make for an important problem that directly influences teaching.

The lack of discipline in physical education, where students have more freedom of movement, creates larger problems of group control than in the classroom [31]. It seems clear that control is a prerequisite for teaching, as Kulinna et al. [32] make clear in their study about bad behaviour in physical education students. They discuss the need to improve teacher education so that teachers may confront and control their students' behaviour problems with the greatest assuredness.

In the Spanish context, it is expectable to face the same problems mentioned in the revised scientific literature. In Spain, there is no mentor who helps the beginning teacher overcome the faced problems in the first years at school. Neither there are studies that analyzed the problems that teachers have within their first teaching experiences. Therefore, the aim of the present study was to identify the problems of novice Spanish physical education teachers. More specifically, the main aim was to identify the situations in which teachers find the most difficulties in their first experiences, in order to evaluate the need for specific education programs. In addition, it was examined whether there were gender differences between the problems of the novice physical education teachers.

\section{METHOD}

A mixed methodology (quantitative and qualitative) was used, combining a questionnaire and an interview, with a similar structure to that used in other studies [27, 33]

\section{Participants}

The sample was composed by 45 primary school physical education teachers ( 17 women and 28 men) between the ages of 22 and 33 years $(M=26.04, S D=3.18)$ and between 1 and 3 years of teaching experience $(M=1.45, S D=.86)$. A selection of novice teachers was carried out acording to a simple random sampling. The questionnaire was sent to teachers who were specialized in physical education and who were approved in public exams to get professional certification in Andalusia (Spain). The questionnaire was completed anonymously and the total number of validated questionnaires received was 45 (69\% of return rate).

\section{Instruments}

Inventory of Teaching Problems (ITP) developed by Jordell [34] to describe an inventory of teaching problems was translated to Spanish [3]. For the translation of the original instrument, the inverse translation strategy was applied, i.e., the items were translated to Spanish and subsequently the scale was translated again to English by another group of translators and compared to the original, finding total coincidence. The original instrument were modified in order to direct the questions specifically to the physical education teachers [4]. The justification for this adaptation is based on a bibliography review, since other research studies have demonstrated that physical education teachers have problems directly related to their class subject $[1,5]$. An initial adaptation was done and later the questionnaire was analyzed by a group of 10 university teachers who were experts in general didactics or physical education. Moreover, the questionnaire was inspected by group of teachers to check the instrument's validity and reliability. After this procedure the results obtained were satisfactory. The scale consisted of 75 items that measured 11 dimensions [4]: teaching (e.g. "Introducing new activities of teaching and learning"), planning (e.g. "Planning a lesson"), evaluation (e.g. "Knowing the students' initial levels"), material resources and facilities (e.g. "Scarcity of specific material in the school"), relationships with students (e.g. "Discipline problems with students or groups of students"), relationships with parents (e.g. "Encountering indifference toward the subject matter by the parents"), relationships with colleagues (e.g. "Cooperating with colleagues"), work conditions and relationships with administrators (e.g. "Disagreements with the school's administrators"), personal (e.g. "Maintaining my private life separate from school life"), environment (e.g. "Distance from the school to my home"), and organization (e.g. "Organizing the physical activities proposed in class"). The scale was captioned by the sentence "According to your personal experience, to what degree has each of these situations been a problem during your first year of teaching experience?". Subjects responded using a Likert scale from 1 (It is not currently nor has it been a problem for me) to 4 (It has been a big problem) [3]. An overall Cronbach's alpha value of .90 was obtained for the questionnaire.

Semi-structured interviews. Interviews were carried out with 6 randomly selected teachers belonging to different 
schools. Following the recommendations by Patton [35], a semi-structured interview was elaborated with questions that were developed based on a few topics or categories, but with the possibility of inquiring further into some of the answers if appropriate. The main parts of the interview plan were: personal information, organization and control of the class, planning, evaluation, social bonds, material resources and facilities, permanent training [3]. For instance, one of the questions was: "According to the evaluation, comment on which were the most important worries you have had". The first draft of the interview guide was reviewed by expert university teachers and secondary school teachers, specialized in physical education. Finally, two interviews were carried out in order to train the evaluators. Interviews were done in person, were recorded, and were literally transcribed in a text processor.

\section{Data Analysis}

Quantitative analysis. This analysis was done with the statistical package SPSS 16.0. First, an analysis of the reliability of the questionnaire was done, and later the descriptive statistics of the different variables were calculated (mean, standard deviation, asymmetry and kurtosis). Finally, it was examined gender differences with the student t-test for independent samples.

Qualitative analysis. The first step in the qualitative analysis was to assign codes to the transcribed text. The codes are abbreviations of words applied to a segment of text (phrase or paragraph) with the goal of classifying it [36]. The codes were grouped in categories or dimensions as was done with the questions from the ITP inventory, with the intent of later finding relationships between the results by triangulation. With regard to the codes, established codes were used in part, though the list of codes was extended during the process of qualitative analysis. To each three-letter code, a number was added to indicate whether the sentence expressed a problem or concern of the teacher (1), a satisfaction (2), or it was neutral ( 0$)$.

The coding process was done by a group of six coders composed of four university expert teachers, a research granted student, and the primary researcher. The training and the process of coding consisted of:

1 Getting familiarized with the list of codes.

2 Coding together to get familiar with the process.

3 Coding the same interview individually and putting the results in agreement.

4 Dividing up the interviews so each person would code two.

5 Combining the coding of all the interviews with an intercoder accordance greater than $80 \%$.

The qualitative analysis was done with the AQUAD 5.0 programme, which facilitated the process of reducing data, counting the codes, and managing the organized texts.

Triangulation. Triangulation was used to compare the results obtained by the two instruments (questionnaires and interviews). Bryman [37] affirms that despite the obstacles in integrating the two methodologies, triangulation of the quantitative and qualitative data offers the researcher advantages such as confidence in the results and the stimulus to outline new theories taken from the study. In the same line, Morgan and Hansen [38] state that "the data source triangulation achieved by combining these two methods would strengthen the findings". The triangulation process was started comparing the mean values of both instruments aspects, which was used as a guide throughout the analysis and comparison of the results. For example, from the quantitative point of view, the organization aspect obtained the highest value. Within this aspect we are going to focus particularly on item 29: discipline problems with students/students groups, which obtained a high mean score $(M=2.18)$. In interviews, the code DIS (discipline) had the greatest frequency with the worry subcode "1"; here we can see some comments from interviewed teachers:

"I have had a lot of problems with children behaviour" (Interview 4, 94-96)

"When I began, they punched and kicked each other... it was horrible" (Interview 1, 1008-1010)

\section{RESULTS}

Table 1 presents the descriptive statistics of the dimensions considered in the questionnaire. The organization dimension had the highest average score $(M=2.23)$, and relationships with colleagues had the lowest average score $(M=1.45)$.

In the individual analysis of each of item, the items with highest mean scores were the following:

1- Item 64. Finding time to organize physical, athletic extracurricular activities, with an average of 2.63. For almost half of the teachers $(46.6 \%)$, this is a considerable or large problem. For $86.1 \%$, it has been or is currently a problem to some degree.

2- Item 57. Scarcity of adequate facilities at the school in which to teach physical education, with an average of 2.50. For $47.7 \%$ of the teachers, this is a considerable problem, and for $72.7 \%$ it has been or is a problem to some degree.

3- Item 44. Scarcity of specific physical education materials in the school, with an average of $2.45 .77 .8 \%$ consider it a problem, and $40 \%$ deem it a considerable problem.

4- Item 32. Indifference toward the subject matter among the parents, with an average of $2.38 .38 .8 \%$ of the teachers regarded this problem of status as considerable.

5- Item 27. Student refusal when teaching methods with which they are not accustomed are used, with an average of 2.22 . Of the teachers, $34.1 \%$ regarded this innovative aspect of the teaching of physical education as a considerable problem.

6- Item 31. Organizing students in homogeneous groups in order to work simultaneously, with an average of 2.19. $65.2 \%$ of the subjects considered this a problem, and $32.6 \%$ regarded it as a considerable problem.

7- Item 29. Discipline problems with students or groups of students, with an average of 2.18 . For $75 \%$ of the teachers, the behaviour of the students has been a problem to some degree. 
Table 1. Descriptive Statistics of All the Dimensions

\begin{tabular}{|l|l|l|l|l|}
\hline Dimension & $M$ & $S D$ & Asymmetry & Kurtosis \\
\hline \hline 1. Teaching & 1.85 & .51 & 1.11 & 1.67 \\
\hline 2. Planning & 1.65 & .46 & .85 & .46 \\
\hline 3. Evaluation & 1.78 & .58 & 1.24 & .47 \\
\hline 4. Material resources and facilities & 2.02 & .58 & .10 & -1.03 \\
\hline 5. Relationships with students & 1.96 & .42 & .25 & .55 \\
\hline 6. Relationships with parents & 1.94 & .48 & .96 & .13 \\
\hline 7. Relationships with colleagues & 1.45 & .49 & 1.38 & 1.64 \\
\hline 8. Work conditions and relationships with administrators. & 1.65 & .47 & .96 & .74 \\
\hline 9. Personal & 1.72 & .68 & 1.66 & 3.78 \\
\hline 10. Environment & 1.77 & .77 & .42 & -.56 \\
\hline 11. Organization & 2.23 & .70 & .58 & .33 \\
\hline
\end{tabular}

$M=$ Mean $S D=$ Standard deviation .

8- Item 69. Low number of weekly physical education class hours with each class, with an average of 2.18. 63.6\% consider it a problem to some degree, and $34.1 \%$ regard it as a considerable problem.

In the student t-test for independent samples analysis, it was observed that there weren't statistically significant gender differences in the problems that novice physical education teachers reported (see Table 2).

With regard to the qualitative analysis, as the primary objective of the study was to identify the problems of novice teachers, the starting point was the relationship between the codes that had a number "1", indicating a problem or concern. In Fig. (1), it is observed that discipline (DIS) is the code that causes the most problems in the teachers that were interviewed. Relationships with colleagues (RCO) and with students (RST) are next, followed by self-esteem
(SES), the role of physical education (RPE), physical education materials (PEM), and the organization of the school (OSC).

In qualitative research, an analysis of the frequency of the codes without specifying the level of satisfaction or concern that was added is normally done. Therefore, the total frequency was calculated next, adding up the codes that have a "0" (descriptive), a "1" (concern), and a "2" (satisfaction). As demonstrated in Fig. (2), the code self-esteem (SES) is emphasized, followed by relationships with colleagues (RCO), and relationships with students (RST). The mostcited codes after these were physical education material (PEM) and discipline (DIS).

In Table $\mathbf{3}$, the dimensions are ordered according to the average frequency of the following codes: problem (1), satisfaction (2), and total. In parentheses the code that was most

Table 2. Analysis of Gender Differences Through the Student t-test for Independent Samples

\begin{tabular}{|c|c|c|c|c|c|c|c|c|}
\hline \multirow[t]{2}{*}{ Variables } & \multicolumn{2}{|c|}{$\begin{array}{l}\text { Male } \\
(n=28)\end{array}$} & \multicolumn{2}{|c|}{$\begin{array}{l}\text { Female } \\
(n=17)\end{array}$} & \multirow[b]{2}{*}{ t-student } & \multirow[b]{2}{*}{$p$} & \multirow[b]{2}{*}{$\boldsymbol{F}$} & \multirow[b]{2}{*}{$r$} \\
\hline & $M$ & $S D$ & $M$ & $S D$ & & & & \\
\hline 1. Teaching & 1.91 & .52 & 1.76 & .48 & .97 & .93 & .00 & .15 \\
\hline 2. Planning & 1.70 & .44 & 1.55 & .50 & 1.08 & .28 & .28 & .16 \\
\hline 3. Evaluation & 1.80 & .45 & 1.74 & .75 & .36 & .72 & 2.17 & .05 \\
\hline 4. Material resources and facilities & 2.04 & .56 & 1.99 & .64 & .26 & .79 & 1.04 & .04 \\
\hline 5. Relationships with students & 2.01 & .38 & 1.87 & .48 & 1.08 & .29 & 1.37 & .16 \\
\hline 6. Relationships with parents & 2.46 & 1.27 & 1.88 & 1.05 & 1.53 & .13 & 1.05 & .25 \\
\hline 7. Relationships with colleagues & 1.41 & .41 & 1.49 & 62 & -.51 & .61 & 2.40 & -.07 \\
\hline 8. Work conditions and relationships with administrators. & 1.73 & .50 & 1.58 & .39 & 1.05 & .30 & 1.22 & .16 \\
\hline 9. Personal & 1.99 & .75 & 1.68 & .52 & 1.51 & .14 & .73 & .23 \\
\hline 10. Environment & 2.27 & .82 & 1.82 & 60 & 1.93 & .06 & 1.78 & .30 \\
\hline 11. Organization & 2.33 & .75 & 2.07 & .60 & 1.19 & .24 & .76 & .19 \\
\hline
\end{tabular}

$M=$ Mean $; S D=$ Standard deviation; $r=$ effect size. 


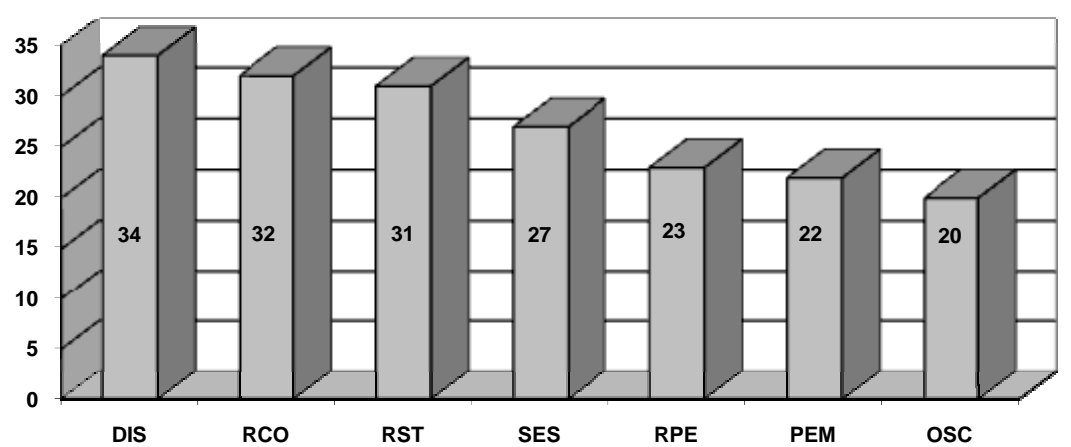

Fig. (1). Frequency of codes that express concern. DIS=Discipline, RCO=Relationships with colleagues, RST=Relationships with students, SES=Self-esteem, RPE=Role of physical education, PEM=Physical education materials, OSC=Organization of the school.

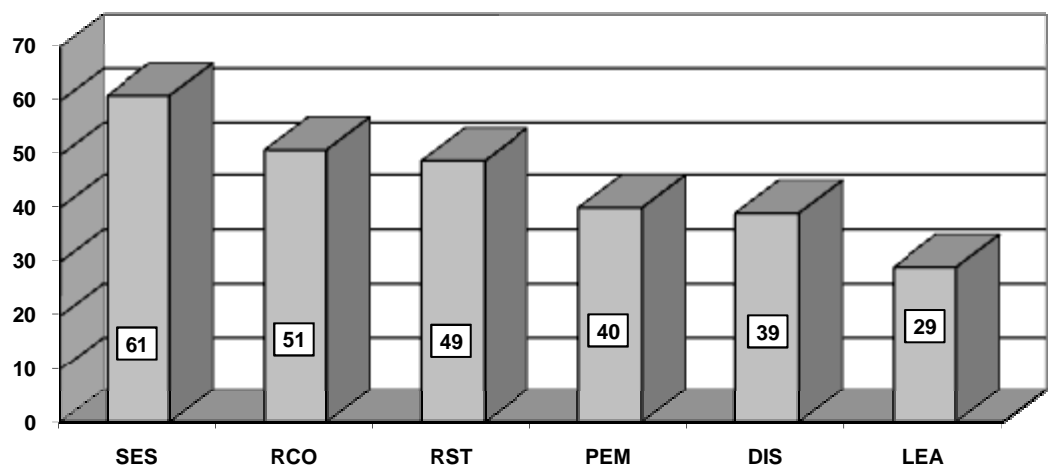

Fig. (2). Total frequency of the codes. SES=Self-esteem, RCO=Relationships with colleagues, RST=Relationships with students, PEM=Physical education materials, DIS=Discipline, LEA=learning.

repeated in each dimension is shown. For these data, the control-organization dimension is emphasized because in the "problem" level, it had the highest average, and in total, it is very close to being the first. The relationships dimension had the highest total average and it is the second both for "problem" and "satisfaction". The personal dimension reached high average values, with an emphasis in "satisfaction". The dimension that most varied between the levels "problem" and "satisfaction" is that of control-organization, and the rest obtained average scores that were similar to the other dimensions.

With regard to the triangulation of the results, the data from the ITP inventory were related to those of the interview to give them more validity and to detect which of the aspects provoke more problems for novice teachers of physical education. The averages of the dimensions from both instruments were compared.

Table 3. Dimensions of the Interviews Ordered by the Average Frequency of the Codes

\begin{tabular}{|c|c|c|c|c|c|c|c|c|c|}
\hline \multicolumn{4}{|l|}{ “1” PROBLEM } & \multicolumn{2}{|l|}{ “2” SATISFACTION } & \multicolumn{4}{|l|}{ TOTAL } \\
\hline Dimension & $\boldsymbol{F}$ & Dimension code & $f$ & Dimension & $\boldsymbol{F}$ & Dimension & $\boldsymbol{F}$ & Dimension code & $f$ \\
\hline $\begin{array}{l}\text { Control- } \\
\text { organization }\end{array}$ & 22.0 & DIS (discipline) & 34 & Personal & 8.7 & Relationships & 28.0 & $\begin{array}{l}\text { RCO (relationship } \\
\text { colleagues) }\end{array}$ & 51 \\
\hline Relationships & 18.2 & RCO (relationship colleagues) & 32 & Relationships & 8 & Control-organization & 27.5 & DIS (discipline) & 39 \\
\hline Personal & 15.5 & SES (self-esteem) & 27 & Material resources and facilities & 4.7 & Personal & 26.5 & SES (self-esteem) & 61 \\
\hline Planning & 14.5 & LTP (long-term planning) & 17 & Control-organization & 4.5 & Planning & 18.5 & $\begin{array}{l}\text { (STP-short-term } \\
\text { planning) }\end{array}$ & 17 \\
\hline $\begin{array}{l}\text { Material resources } \\
\text { and facilities }\end{array}$ & 12.3 & PEM (PE material) & 22 & Teaching & 3.6 & $\begin{array}{l}\text { Material resources and } \\
\text { facilities }\end{array}$ & 18.3 & PEM (PE material) & 40 \\
\hline Environment & 8.3 & $\mathrm{SCH}$ (school) & 16 & Planning & 3.5 & Teaching & 13.0 & LEA (learning) & 29 \\
\hline Teaching & 7.8 & LEA (learning) & 18 & Continuing education & 1.5 & Environment & 11.0 & $\mathrm{SCH}$ (school) & 22 \\
\hline Evaluation & 6.3 & GRA (grading) & 16 & Environment & 1.3 & Continuing education & 10.8 & (COU- course taken) & 27 \\
\hline $\begin{array}{l}\text { Continuing } \\
\text { education }\end{array}$ & 5.0 & $\begin{array}{l}\text { NCE (need for continuing } \\
\text { education) }\end{array}$ & 10 & Evaluation & 1.3 & Evaluation & 10.0 & GRA (grading) & 26 \\
\hline
\end{tabular}

$F=$ mean frequency; $f=$ total frequency of the most scored code in each dimension. 
Table 4. Comparison of the Dimension Data from the Questionnaire and the Interview

\begin{tabular}{|l|l|l|l|}
\hline ISE INVENTORY & \multicolumn{2}{l|}{ INTERVIEW ANALYSIS } \\
\hline Dimension & $\boldsymbol{M}$ & Dimension & $\boldsymbol{F}$ \\
\hline \hline Organization & 2.23 & Control-organization & 22.0 \\
\hline Material resources and facilities & 2.02 & Relationships & 18.2 \\
\hline Relationships with students & 1.96 & Personal & 15.5 \\
\hline Relationships with parents & 1.94 & Planning & 14.5 \\
\hline Teaching & 1.85 & Material resources and facilities & 12.3 \\
\hline Evaluation & 1.78 & Environment & 8.3 \\
\hline Environment & 1.77 & Teaching & 7.8 \\
\hline Personal & 1.72 & Evaluation & 6.3 \\
\hline Planning & 1.65 & Continuing education & 5.0 \\
\hline Work conditions and relationship with administration & 1.65 & & \\
\hline Relationships with colleagues & 1.45 & & \\
\hline
\end{tabular}

$M=$ mean score; $F=$ mean frequency.

A) Organization and Control Dimension. In Table $\mathbf{4}$ it is demonstrated that for both instruments the organization dimension was the dimension that caused the most problems for the physical education teachers. Within these dimensions, discipline is emphasized because in the questionnaire, item 29, problems with the discipline of students or groups of students, with an average of 2.18 , was one of the highest. In the interviews, the DIS (discipline) code was the one that most frequently had the subcode "1" for concern:

“Discipline Problems affect my classes a lot" (Interview 6, 632-634)

Class control in physical education was a problem cited both in the questionnaire (item 1, with an average of 1.95) and during the interview (code GEC for general control, with a frequency of 17) and a prerequisite for being able to teach:

"In physical education class, the most important thing was to control the situation" (interview 2, 100-102).

B) Relationship Dimension. This aspect showed a great frequency in the comments of the beginning teachers interviewed, in fact, it was the second one with the highest frequency; while in the questionnaire the relationships with the students (1.96) and with the parents (1.94) occupied the third and fourth positions, respectively. Behaviour problems were repeated, since they were in the organization dimension, and the lack of time to get to know the students (item 28 of the questionnaire) is emphasized, because with an average score of 2.16 , it was one of the most problematic. Some examples taken from the interviews, about the problems between beginning teachers and their students:

"It took some effort to specify how far I must go and how far they can go" (Interview 4, 313-321)

"They first observe you and then see if they can take you to their ground and rule over the class you are teaching" (Interview 2, 395-400)
C) Material resources and facilities Dimension. The material resources tend to be one of the unsettled subjects of physical education, as was demonstrated by being the second-most problematic dimension in the questionnaire (2.02). The qualitative analysis reinforces the important of item 57, scarcity of adequate facilities in the school to teach physical education, which was given the secondhighest score (2.50 on average). In the interviews, the code FAC (facilities) was repeated 14 times with the code "1" for concern, highlighting the lack of a specific classroom:

"Well, the biggest problem is that there is no adequate classroom in case of rain, wind, cold, etc..." (interview 4, 121-126).

Likewise, the third most problematic item was 44, scarcity of specific physical education materials at the school, with an average of 2.45. Also, in the interviews, the code PEM (physical education materials) was repeated 22 times, making mention of this eternal problem for the physical education teacher:

"Another problem is the material, you have very little material, you don't have the necessary material to be able to work" (interview 1, 1151-1154).

D) Teaching Dimension. The teaching dimension obtained an intermediate evaluation on the questionnaires (1.85) and a rather low frequency in the interviews (7.8). However, it brought about aspects that were truly interesting. For example, it coincides that motivation had one of the lowest values on the ITP inventory (item 3, with an average of 1.34), and in the interview, the code MOT (motivation) was repeated 11 times with the subcode of satisfaction, occupying the fifth-greatest frequency:

"Very gratifying, every time that I would utilize something new; I would get to class and they would applaud if one day I would come with the cassette player. Later they thanked me" (interview 6, 94-100). 
One complaint of teachers who were specialized in physical education is to teach other classes (item 67 with an average of 1.94):

"My situation is that I don't see myself teaching English and I have nine hours of English, almost more than physical education" (interview 4, 45-48).

E) Personal Dimension. This dimension had low scores in the questionnaire (average of 1.72), while in the interview, it was the third most-frequently cited with the subcode of concern ( 15.5 on average). The explanation for this difference is that on the one hand in the interviews, teachers tended to talk more about themselves than in the questionnaire, as can be verified with the code SES (selfesteem), which has the highest total frequency (61 times). On the other hand, the personal dimension in the interviews includes the status problem of this class (RPE code that is repeated 23 times) which also had high scoring in item 32 (parents with an average of 2.38), item 66 (colleagues with an average of 1.69) and item 73 (students with an average of 1.67) on the ITP inventory:

"Among the faculty, I have many colleagues that do not value physical education” (interview 2, 294-296).

F) Planning Dimension. In this dimension, something similar to the last dimension occurs. On the one hand, in the ITP inventory, results obtained showe a low score with an average of 1.65 , while in the interviews, it was the fourth-most problematic with an average frequency of 14.5. In the qualitative analysis, it has been verified that the problems of planning and the scarcity of facilities and material are related, which provokes this difference. Both instruments coincide in the lack of time to plan (item 47 with an average of 1.95) and the initial work it takes:

"I didn't have any time; I would take the time to thoroughly prepare the session, and later it wouldn't even go well" (interview 6, 502-506).

$G)$ Evaluation Dimension. The evaluation dimension was not very problematic, as cited in both the questionnaire (1.78) and the interview (6.3). The explanation may be that the teachers that are in their first year have not yet had to go through the most conflicting situation which is giving a final grade (item 61, with an average of 1.90) [3].

\section{DISCUSSION}

The purpose of the present study was to identify the problems of novice Spanish physical education teachers. The results emphasized the problems of organization and control, material resources and facilities, and the relationships with students and parents. Part of these results are similar to those found in similar studies [5, 39], such as in the case of organization, management, and control of the class or the difficulties in relating to the parents of the students. Due to the specific physical education characteristics, other problems related to the scarcity of resources were brought to light. Likewise, in the present study, major problems of motivation among students were not found; motivation appears in the interviews as one of the codes that were most satisfactory for the teachers.

Students enjoy physical education and they have fun in this class, but they relate it to recess time due to the total freedom that they have had with some teachers, and therefore control and occasionally motivation are converted in tasks that are especially difficult.

The most important problem that is demonstrated in the present study was organizing and controlling the class, and this may be due to the differences between a physical education class and a traditional classroom class, caused by the use of an open facility. While in the classroom the students have a formal and predetermined initial structure, in the gymnasium or athletic field they have to start class already resolving this problem. Worse yet, physical education class consists of executing numerous motor activities, generally with elements of fun and with material. This is frequently associated by the pupils with break time or informal activities, which makes the control of the group even more difficult. For these and other reasons, numerous studies [31, 40, 41] pointed out some aspects such as discipline, group control, and organization of the activities as the most problematic aspects with which teachers of this subject are faced. In our research, these data are again confirmed. However, these teachers significantly improve in this didactical aspect as the year goes on, according to Vonk [11], because the students observe greater assuredness and confidence in the teacher. The teacher learns to apply rules and resources to achieve class control, and experience is important for this. In this sense, collaboration or supervision by a mentor that could help the beginning teacher to face the control and organization of the class would be beneficial, since different studies have found that tutored teaching experiences have a positive effect on the development of the capabilities of beginning teachers $[12,42]$

In Spain, despite the adapting problems teachers have during their first years of experience, the mentor teacher character does not exist as such. If we revise the literature we see that mentor teachers represent relevant support and help for the professional development of beginning teachers. For instance, the results obtained from studies such as those performed by Smith and Ingersoll [8], where it was proved that beginning teachers that received mentor support were less probable to leave to other schools or give up the teaching career after their first year. More recently, some studies [4345] measured the impact of a one-year long participation with mentor teachers. In general, mentors and novice teachers developed a more positive view of both their psicological state and the support from the school social environment [42]. Therefore the effective selection and preparation of mentors are really important to improve his influence about beginning teachers $[45,46]$.

The role of physical education in schools is still secondary, as these teachers who specialize in physical education confirmed in all of the interviews. Colleagues, students, administrators, and parents have demonstrated the low status that the physical education subject still has [30].

Quantitatively, item 32, "indifference among parents toward the material", on the ITP inventory, was the fourthmost problematic, with an average of 2.38. Qualitatively, this situation was analyzed in the interviews by some teachers. This low status is not exclusive of our context, as studies by Sparkes et al. [47] and Schempp [28] have demonstrated. The unfamiliarity with this science explains the rejection of 
physical education in contrast to the social importance of sport [29].

The results of the study demonstrated that one of the most problematic items in the questionnaire is the scarcity of adequate facilities. Further, the dimension with the secondhighest average score in the questionnaires is that which refers to the material resources and facilities. In the interviews, the scarcity of materials and economic resources to acquire them is mentioned, as well as the absence of gymnasiums and adequate spaces for physical education. Due to the aforementioned status, the scarcity of resources to teach this class is a constant complaint of physical education teachers, as Morgan and Hansen [38] argued, that they consider it a barrier that influences the quality of physical education programmes.

The physical education teachers, especially in the interviews, demand a continuing education based on reflection, responding to the specific needs of each school, with a methodology is more participative and inductive; and supervised by expert, mentor teachers [48, 49].

\section{CONCLUSIONS}

The primary purpose of this study was to identify the most important problems of novice Spanish physical education teachers. From the results of this study and their comparison with other similarly studies $[1,3,5,10,17]$, the following conclusions can be drawn:

a Novice physical education teachers find themselves in a conflictive situation during their first few teaching experiences, which is aggravated by diverse specific problems such as status, scarcity of material resources and facilities, and greater difficulty with organization and control.

b In the Spanish context, we have found problems in beginning teachers of physical education similar to those found in other studies with samples from the United Kingdom and the U.S.A.

c The results obtained from this research show that, throughout university training for physical education teachers, greater importance must be placed on class control and organization, social skills and comunication, the use and construction of alternative materials for physical education, etc.

d It is necessary to establish continuing educational programmes for teachers when they are being incorporated into a school, particularly during their first few years of teaching.

e Moreover, we believe the use of a mentor teacher to support beginning teachers during their first working experiences to be interesting and beneficial.

\section{REFERENCES}

[1] Hutchins C, MacDonald D. Beginning physical education teachers and early career decision-making. Phys Educ Rev 1993; 16(2): 151-61.

[2] Bransford J, Darling-Hammond L, LePage P. In: DarlingHammond L, Bransford J, Eds. Preparing teachers for a changing world. S. Francisco: Jossey Bass 2005; pp. 1-39.

[3] Marcelo C. Aprender a enseñar: un estudio sobre el proceso de socialización de profesores principiantes. Madrid: C.I.D.E. 1992.

[4] Sáenz-López P. The training of the physical education beginner teacher. USA: ProQuest. Information \& Learning 2004.
[5] Veenman S. Perceived problems of beginning teachers. Rev Educ Res 1984; 54: 143-78.

[6] Macdonald D. Teacher attrition: a review of literature. Teach Teach Edu 1999; 15: 835-48.

[7] Flores MA. Being a novice teacher in two different settings: Struggles, continuities, and discontinuities. Teachers Coll Rec 2006; 108: 2021-52.

[8] Smith TM, Ingersoll RM. What are the effects of induction and mentoring on beginning teacher turnover? Am Educ Res J 2004; 41: 681-714.

[9] Johnston NA, Rastoy EW, Holdaway EA, Friesen D. The induction of teachers: a major internship program. J Teach Edu 1993; 44: 296-304.

[10] Herbert E, Worthy T. Does the first year of teaching have to be a bad one? A case study of success. Teach Teach Edu 2001; 17: 897911.

[11] Vonk JHC. In: McBride R., Ed. Teacher Education Policy: Some Issues Areising from Research and Practice. London, Falmer Press 1996; pp. 113-34.

[12] Haverback HR, Parault SJ. Pre-service reading teacher efficacy and tutoring: a review. Educ Psychol Rev 2008; 20: 237-55.

[13] Curtner-Smith MD, Hastie PA, Kinchin GD. Influence of occupational socialization on beginning teachers' interpretation and delivery of sport education. Sport Educ Soc 2008; 13: 97-117.

[14] Keay J. Learning from other teachers: Gender influences. Eur Phys Educ Rev 2007; 13: 209-27.

[15] Velija P, Capel S, Katene W, Hayes S. 'Does knowing stuff like PSHE and citizenship make me a better teacher?': Student teachers in the teacher training figuration. Eur Phys Educ Rev 2008; 14: 389-406.

[16] Goodnough K, Osmon P, Dibbon D, Glassman M, Stevens K. Exploring a triad model of student teaching: Pre-service teacher and cooperating teacher perceptions. Teach Teach Educ 2009; 25 : 285-96.

[17] Schmidt M, Knowles JG. Four women's stories of "failure" as beginning teachers. Teach Teach Edu 1995; 11: 429-44.

[18] Admiraal WF, Korthagen FAJ, Wubbels T. Effects of student teachers' coping behavior. Br J Educ Psychol 2000; 70: 33-52.

[19] Cothran DJ, Kulinna PH. Students' report of misbehavior in physical education. Res Q Exerc Sport 2007; 78: 216-24.

[20] Kohn A. Beyond discipline: from compliance to community. Harv Educ Rev 1997; 67: 611-3.

[21] Geva-May I, Dori YJ. Analysis of an Induction Model. Br J Serv Educ 1996; 22: 333-54.

[22] Briton E, Paine L, Pimm D, Raizen S. Comprehensive Teacher Induction. Dordrecht: Klumer Academic Press 2002.

[23] Sardo-Brown D. A Longitudinal study of novice secondary teachers' planning: year two. Teach Teach Edu 1996; 12: 519-30.

[24] Tjeerdsma BL, Metzler MW. Making decisions for program improvement. J Teach Phys Educ 2000; 19: 538-42.

[25] Matanin M, Collier C. Longitudinal analysis of preservice teachers beliefs about teaching physical education. J Teach Phys Educ 2003; 22: 153-68.

[26] Richardson V, Placier P. In: Richardson V., Ed. Handbook of Research on Teaching. $4^{\text {th }}$ ed. New York: American Educational Research Association 2001; pp. 905-47.

[27] Morgan PJ, Hansen V. The relationship between PE biographies and PE teaching practices of classroom teachers. Sport Educ Soc 2008; 13: 373-91.

[28] Schempp PG. Constructing Professional Knowledge: a case study of an experienced high school teacher. J Teach Phys Educ 1993; 13: 3-25.

[29] Templin TJ, Sparkes A, Grant B, Schempp P. Matching the self: the paradoxical case and life history of a late career teacher/coach. J Teach Phys Educ 1994; 13: 274-94.

[30] Smyth DM. First-year physical education teachers perceptions of their workplace. J Teach Phys Educ 1995; 14: 198-214.

[31] Perron J, Downey PJ. Management techniques used by high school physical education teachers. J Teach Phys Educ 1997; 17: 72-84.

[32] Kulinna PH, Cothran DJ, Regualos R. Teachers reports of student misbehavior in physical education. Res Q Exerc Sport 2006; 77: 32-40.

[33] Wright SC. The socialization of singaporean physical educators. J Teach Phys Educ 2001; 20: 207-26.

[34] Jordell KO. Problems of beginning and more experienced teachers in Norway. Scand J Educ Res 1985; 29: 105-21. 
[35] Patton MQ. Qualitative evaluation and research methods. $2^{\text {nd }}$ ed. Newbury Park, CA: Sage Publications 1990.

[36] Miles M, Huberman A. Qualitative data analysis. $2^{\text {nd }}$ ed. California: Sage Publications 1994.

[37] Bryman A. Barriers to integrating quantitative and qualitative research. J Mixed Meth Res 2007; 1: 1-18.

[38] Morgan PJ, Hansen V. Classroom teachers' perceptions of the impact of barriers to teaching physical education on the quality of physical education program. Res Q Exerc Sport 2008; 79: 506-16.

[39] Britton E, Paine L, Pimm D, Raizen S. Comprehensive teacher induction. Dordrecht: Klumer Academic Press 2002.

[40] Bertone S, Meard J, Euzert JP, Ria L, Durand M. Intrapsychic conflict experienced by a preservice teacher during classroom interactions: a case study in physical education. Teach Teach Educ 2003; 19: 113-25.

[41] Toren Z, LLiyan S. The problems of the beginning teacher in the Arab schools in Israel. Teach Teach Educ 2008; 24: 1041-56.

[42] Chaliès S, Bertone S, Flavier E, Durand M. Effects of collaborative mentoring on the articulation of training and classroom situations: A case study in the French school system. Teach Teach Educ 2008; 24: 550-63.
[43] Kulinna PH, McCaughtry N, Martin JJ, Cothran D, Faust R. The influence of professional development on teachers' psychosocial perceptions of teaching a health-related physical education curriculum. J Teach Phys Educ 2008; 27: 292-307.

[44] Lofstrom E, Eisenschmidt E. Novice teachers perspectives on mentoring: The case of the Estonian induction year. Teach Teach Educ 2009; 25: 681-9.

[45] Rikard GL, Banville D. Effective mentoring: critical to the professional development of first year physical educators. J Teach Phys Educ 2010; 29: 245-61.

[46] Hobson AJ, Ashby P, Malderez A, Tomlinson PD. Mentoring beginning teachers: What we know and what we don't. Teach Teach Educ 2009; 25: 207-16.

[47] Sparkes A, Templin TJ, Schempp PG. Exploring dimensions of marginality: Reflecting on the life histories of physical education teachers. J Teach Phys Educ 1993; 12: 386-98.

[48] Curtner-Smith MD. The occupational socialization of a first year P.E. teacher with a teaching orientation. Sport Educ Soc 2001; 6: 81-106.

[49] Keay J. Mentoring newly qualified physical education teachers support or development? Br J Teach Phys Educ 2000; 31: 41-3.

(C) Sáenz-López et al.; Licensee Bentham Open.

This is an open access article licensed under the terms of the Creative Commons Attribution Non-Commercial License (http://creativecommons.org/licenses/ by-nc/3.0/) which permits unrestricted, non-commercial use, distribution and reproduction in any medium, provided the work is properly cited. 